Article

\title{
Transition from Simple V-V to V-A and Hybrid ECMO Configurations in COVID-19 ARDS
}

\author{
Piotr Suwalski ${ }^{1,+}{ }^{\dagger}$ Jakub Staromłyński ${ }^{1,+}{ }^{\dagger}$ Jakub Brączkowski ${ }^{1}$, Maciej Bartczak ${ }^{1}$, Silvia Mariani ${ }^{2}$, \\ Dominik Drobiński ${ }^{1}$, Konstanty Szułdrzyński ${ }^{3}$ (D), Radosław Smoczyński ${ }^{1}$, Marzena Franczyk ${ }^{1}$, \\ Wojciech Sarnowski ${ }^{1}$, Agnieszka Gajewska ${ }^{1}$, Anna Witkowska ${ }^{1}$ D, Waldemar Wierzba ${ }^{4,5}$, Artur Zaczyński ${ }^{4}$, \\ Zbigniew Król ${ }^{4}$ (D), Ewa Olek ${ }^{1}$, Michał Pasierski ${ }^{1}$, Justine Mafalda Ravaux ${ }^{2}$, Maria Elena de Piero ${ }^{2,6}$, \\ Roberto Lorusso ${ }^{2}$ (D) and Mariusz Kowalewski $1,2,7, *$ (D)
}

\section{check for} updates

Citation: Suwalski, P.; Staromłyński, J.; Brączkowski, J.; Bartczak, M.; Mariani, S.; Drobiński, D.; Szułdrzyński, K.; Smoczyński, R.; Franczyk, M.; Sarnowski, W.; et al. Transition from Simple V-V to V-A and Hybrid ECMO Configurations in COVID-19 ARDS. Membranes 2021, 11, 434. https://doi.org/10.3390/ membranes 11060434

Academic Editor: Dinis Reis Miranda

Received: 19 May 2021

Accepted: 4 June 2021

Published: 9 June 2021

Publisher's Note: MDPI stays neutral with regard to jurisdictional claims in published maps and institutional affiliations.

Copyright: (C) 2021 by the authors. Licensee MDPI, Basel, Switzerland. This article is an open access article distributed under the terms and conditions of the Creative Commons Attribution (CC BY) license (https:/ / creativecommons.org/licenses/by/ $4.0 /)$.
1 Department of Cardiac Surgery, Central Clinical Hospital of the Ministry of Interior, Centre of Postgraduate Medical Education, 02-507 Warsaw, Poland; suwalski.piotr@gmail.com (P.S.); jakubstaromlynski@gmail.com (J.S.); kuba.braczkowski@gmail.com (J.B.); mcjbrtczk@gmail.com (M.B.); dominik.drobinski@gmail.com (D.D.); radek.sm@gmail.com (R.S.); marzena.franczyk@cskmswia.pl (M.F.); wojciech.sarnowski@cskmswia.pl (W.S.); agnieszka.gajewska@cskmswia.pl (A.G.); vera@rallywitkowscy.pl (A.W.); ewa.olek.98@wp.pl (E.O.); michalpasierski@gmail.com (M.P.)

2 Cardio-Thoracic Surgery Department, Heart and Vascular Centre, Maastricht University Medical Centre, 6229 HX Maastricht, The Netherlands; s.mariani1985@gmail.com (S.M.); jmravaux@hotmail.com (J.M.R.); marieledep@gmail.com (M.E.d.P.); roberto.lorussobs@gmail.com (R.L.)

3 Department of Anesthesiology and Intensive Care, Central Clinical Hospital of the Ministry of the Interior and Administration, 02-507 Warsaw, Poland; konstantys@gmail.com

4 Central Clinical Hospital of the Ministry of the Interior and Administration, 02-507 Warsaw, Poland; wwierzba@post.pl (W.W.); artur.zaczynski@cskmswia.pl (A.Z.); zbigniew.krol@cskmswia.pl (Z.K.)

5 Satellite Campus in Warsaw, University of Humanities and Economics in Lodz, 90-212 Warsaw, Poland

6 Department Anaesthesia-Intensive Care, San Giovanni Bosco Hospital, 80144 Turin, Italy

7 Thoracic Research Centre, Collegium Medicum, Nicolaus Copernicus University, Innovative Medical Forum, 87-100 Bydgoszcz, Poland

* Correspondence: kowalewskimariusz@gazeta.pl; Tel.: +48-502269240

+ First two authors contributed equally.

Abstract: In SARS-CoV-2 patients with severe acute respiratory distress syndrome (ARDS), VenoVenous Extracorporeal Membrane Oxygenation (V-V ECMO) was shown to provide valuable treatment with reasonable survival in large multi-centre investigations. However, in some patients, conversion to modified ECMO support forms may be needed. In this single-centre retrospective registry, all consecutive patients receiving V-V ECMO between 1 March 2020 to 1 May 2021 were included and analysed. The patient cohort was divided into two groups: those who remained on $\mathrm{V}-\mathrm{V}$ ECMO and those who required conversion to other modalities. Seventy-eight patients were included, with fourteen cases (18\%) requiring conversions to veno-arterial (V-A) or hybrid ECMO. The reasons for the ECMO mode configuration change were inadequate drainage (35.7\%), inadequate perfusion $(14.3 \%)$, myocardial infarction $(7.1 \%)$, hypovolemic shock $(14.3 \%)$, cardiogenic shock $(14.3 \%)$ and septic shock $(7.1 \%)$. In multivariable analysis, the use of dobutamine $(p=0.007)$ and a shorter ICU duration ( $p=0.047$ ) predicted the conversion. The 30-day mortality was higher in converted patients ( $\log$-rank $p=0.029)$. Overall, only 19 patients $(24.4 \%)$ survived to discharge or lung transplantation. Adverse events were more common after conversion and included renal, cardiovascular and ECMO-circuit complications. Conversion itself was not associated with mortality in the multivariable analysis. In conclusion, as many as $18 \%$ of patients undergoing V-V ECMO for COVID-19 ARDS may require conversion to advanced ECMO support.

Keywords: extracorporeal life support; extracorporeal membrane oxygenation; acute respiratory distress syndrome; cardiogenic shock; COVID-19; SARS-CoV-2 


\section{Introduction}

The use of Extracorporeal Membrane Oxygenation (ECMO) as support for adult patients diagnosed with acute respiratory distress syndrome (ARDS) has dramatically increased in the last decades and particularly during the 2009 H1N1 pandemic and the SARS-CoV-2 pandemic [1,2]. While the veno-venous (V-V) configuration represents the mainstay of ECMO therapy for refractory respiratory failure [3,4], a subset of patients might experience hemodynamic instability, inadequate drainage and perfusion or worsening cardiac dysfunction requiring conversion to other ECMO modes, mainly veno-arterial (V-A) or hybrid ECMO configurations [5,6].

Adults suffering from respiratory failure and requiring V-A or hybrid ECMO have historically had poor outcomes, with prohibitively high bleeding, stroke and mortality rates [7-9]. Some of these disparities in outcomes may be a result of the increased complexity and severity of these patients. It is, thus, mandatory to early identify ARDS patients at risk of ECMO configuration change to apply such modification in a timely manner and/or prevent catastrophic outcomes.

This is particularly true for patients diagnosed with coronavirus disease 2019 (COVID19), a clinical manifestation of severe acute respiratory syndrome coronavirus 2 (SARSCoV-2). Although clinical manifestations of COVID-19 are mainly respiratory, 20-25\% of patients develop some degree of cardiovascular compromise [10-12]. When this happens in patients already supported by V-V ECMO, it might lead to cardiogenic shock, right ventricular failure, life-threatening arrhythmias or even cardiac arrest. In these cases, the $\mathrm{V}-\mathrm{V}$ ECMO is not sufficient nor adequate to counteract such adverse events and a shift toward V-A or hybrid ECMO modes might be required. However, the literature is still lacking robust data on this specific patient cohort.

The aim of this study is to present an analysis from a single high-volume COVID-19 hub to describe the characteristics of COVID-19 patients requiring conversion from V-V to other ECMO configurations, the overall outcome, and to identify potential predictors for ECMO upgrades.

\section{Materials and Methods}

\subsection{Study Design and Patient Population}

This observational retrospective study was based on our institutional registry, which prospectively included all consecutive cases of COVID-19 ECMOs admitted to the Centre of Extracorporeal Therapies (CET-Warsaw, Poland) between 1 March 2020 to 1 May 2021. The CET has been serving as third level COVID-19 reference hub and, in the same time, a subunit of the Clinical Department of Cardiac Surgery, using the expertise of cardiac anaesthetists, cardiac surgeons, cardiologists, perfusionists, and intensivists and admitting patients from the entire voivodeship and beyond.

Recently, due to the growing number of patients requiring extracorporeal therapy, the CET has expanded and now includes the general Department of Anaesthesiology and Intensive Care (Central Clinical Hospital of the Ministry of Interior and Administration). The details on CET have been described elsewhere [13]. Adult patients were included in the registry if they were candidates for ECMO therapy and tested positive for SARS-CoV-2 Infection.

Patients also had to have met the criteria for ECMO support in acute refractory respiratory failure (ARRF) as described by the Board of Intensive Care document and adopted by the Agency for Health Technology Assessment and Tariff System (AOTMIT) [14]. This retrospective analysis of the registry excluded patients primarily supported with V-A ECMO and other advanced support configurations. Patients requiring multiple ECMO runs and patients on ECMO at the time of the data analysis were also excluded.

Finally, patients included in the analysis were categorized in two groups: those who remained on $\mathrm{V}-\mathrm{V}$ ECMO and those who underwent conversion from $\mathrm{V}-\mathrm{V}$ to other forms of support including V-A, veno-venoarterial (V-VA), venoveno-arterial (VV-A), veno-venovenous $(\mathrm{V}-\mathrm{VV})$, venoveno-venous $(\mathrm{VV}-\mathrm{V})$ or other configurations with multiple cannulations. The decision for ECMO configuration change was taken by the local ECMO 
heart team. Unfractionated heparin (UFH) was administered at ECMO start with an initial bolus of $50 \mathrm{U} / \mathrm{kg}$ and titrated to maintain an activated clotting time $>150 \mathrm{~s}$. In patients for whom major bleeding occurred, the UFH infusion was stopped. This study was approved by the Institutional Review, and patient consent for inclusion in the registry was waived.

\subsection{End-Points and Definitions}

The primary end-point was early mortality defined as mortality (of any cause) during index hospitalization or within 30-days of ECMO start. Secondary end-points were complications as identified through the application of institutional protocols and Extracorporeal Life Support Organization (ELSO) definitions [15].

The collected variables were grouped before analysis as follows: demographic data, comorbidities, laboratory data, medications and ECMO course data. Transesophageal echocardiography (TEE) was performed to assess ventricular function and determine the positioning of the ECMO cannulas. All patients underwent computed tomography to determine the extent of pulmonary involvement.

\subsection{Statistical Analysis}

Demographic and clinical variables are expressed as a count (with percentage) for categorical variables and the mean ( \pm standard deviation) or median (interquartile range, IQR) for continuous variables after evaluation for normality. Group comparisons were made using the Mann-Whitney $U$ test where appropriate for the continuous variables and Pearson's $\chi^{2}$ or Fisher's exact test for categorical variables. A two-tailed $p$-value of $<0.05$ was considered significant. To evaluate the risk predictors of in-hospital mortality, variables that achieved a $p$ value of less than 0.2 in the univariable analysis were examined using multivariable analysis with forward stepwise logistic regression.

The following pre-ECMO variables were included in the multivariable analysis: age, weight, days of mechanical ventilation, mean airway pressure, $\mathrm{pH}$, serum bicarbonate, mean arterial pressure, year of ECMO, pre-ECMO disease and conditions, on-ECMO drugs and interventions, and on-ECMO complications. Complications occurring in both groups are reported as a number (\%) with the corresponding odds ratios (ORs) and 95\% CIs. Analyses were performed using SPSS 26.0 (IBM, Armonk, NY, USA).

\section{Results}

Figure 1 represents the patient flow during the study process. During the course of the study, 78 patients underwent V-V ECMO therapy for COVID-19-induced ARDS, which constituted 5.5\% of all 1409 COVID-19 ARDS ICU admissions. Fourteen (18\%) of those required conversions to modified forms of ECMO support for the following reasons: inadequate drainage (35.7\%), inadequate perfusion (14.3\%), acute myocardial infarction (AMI) (7.1\%), hypovolemic shock (14.3\%), cardiogenic shock $(14.3 \%)$ and septic shock $(7.1 \%)$. The baseline characteristics of the two groups are listed in Table 1. Patients undergoing transition to modified ECMO support were younger and less often had comorbidities but none of the differences reached statistical significance.

Table 2 lists ECMO therapy-related details. There were no differences between patients who subsequently underwent conversion and those who remained on $\mathrm{V}-\mathrm{V}$ ECMO with respect to the initial ECMO variables, except for the use of dobutamine, which was required more often in the conversion group $(10.9 \%$ vs. $35.7 \% ; p=0.023)$. The median pro-BNP values during the first $24 \mathrm{~h}$ were $395 \mathrm{pg} / \mathrm{mL}$ (IQR: 184-1855) in the V-V ECMO group and $909 \mathrm{pg} / \mathrm{mL}$ (IQR: 478-6354) in the conversion group but with no significant differences $(p=0.209)$.

The mean time to conversion was 6.5 days. In the univariable analysis, none of the variables assessed (Appendix A-Table A1) were significantly predictive of conversion to other forms of ECMO therapy. In multivariable analysis, however, the use of dobutamine $(p=0.007)$ and a shorter ICU duration $(p=0.047)$ predicted conversion. When limited to arterial conversion mode ( $\mathrm{V}-\mathrm{V}$ to $\mathrm{V}-\mathrm{A}, \mathrm{V}-\mathrm{V}$ to $\mathrm{VV}-\mathrm{AV}$ and $\mathrm{V}-\mathrm{V}$ to $\mathrm{V}-\mathrm{VA}$ ), a shorter ICU 
time, younger age, shorter time on ECMO and lower BMI and BSA, together with higher $\mathrm{FiO}_{2}$, ferritine and alanine transaminase were predictive of conversion in the univariable analysis as well.

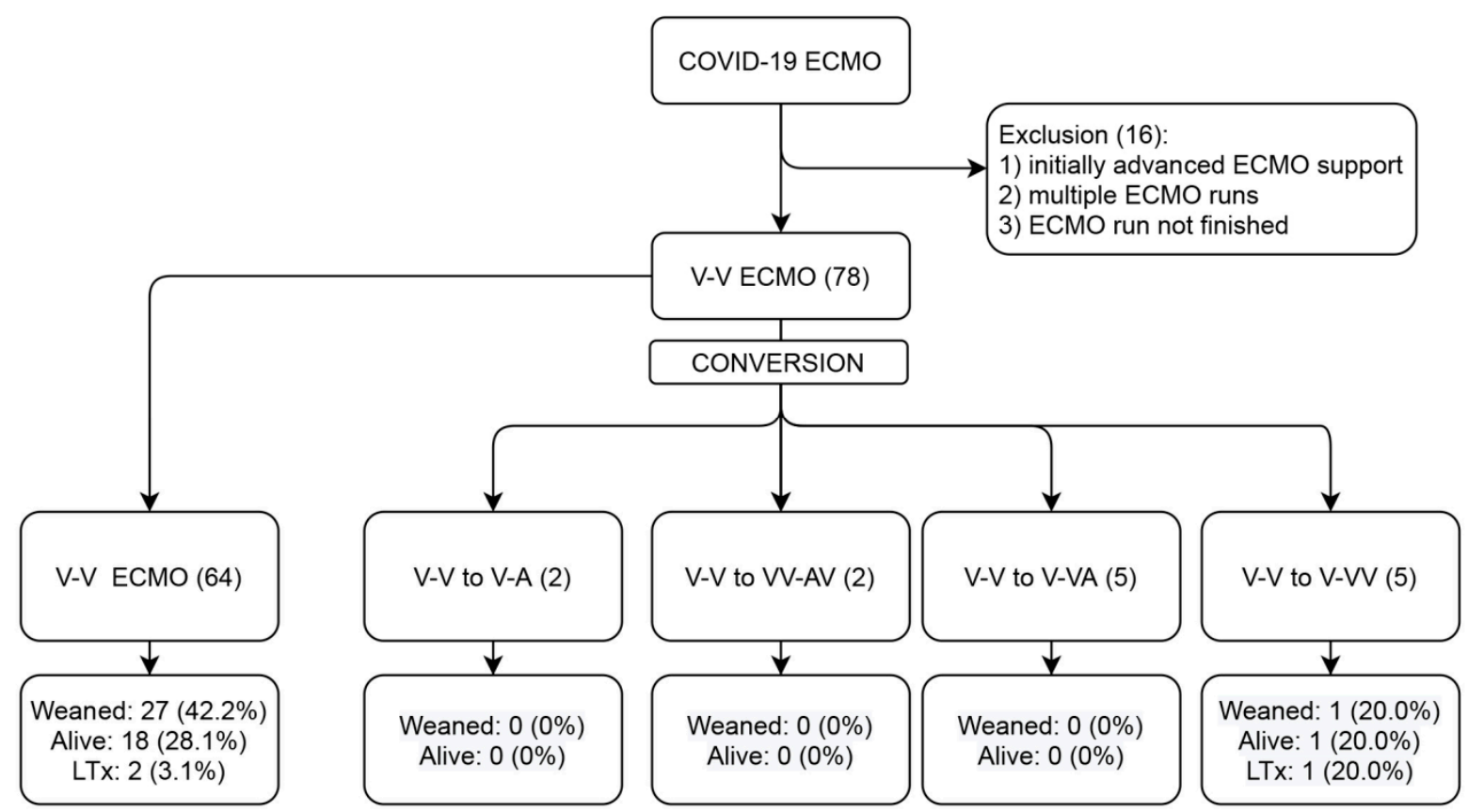

Figure 1. Study flow diagram. ECMO, extracorporeal membrane oxygenation; V, venous; A, arterial; and LTx, lung transplantation.

Table 1. Baseline patient characteristics.

\begin{tabular}{ccccc}
\hline Variable & Total (78) & V-V ECMO (64) & ECMO Conversion (14) & $p$ Value \\
\hline Age & $47.0 \pm 11.3$ & $48.3 \pm 10.0$ & $44.6 \pm 12.2$ & 0.228 \\
Female & $18(23.1 \%)$ & $15(23.4 \%)$ & $3(21.4)$ & 0.872 \\
BMI $\left(\mathrm{kg} / \mathrm{m}^{2}\right)$ & $31.3 \pm 9.5$ & $32.6 \pm 8.6$ & $30.6 \pm 10.5$ & 0.449 \\
BSA (m $\left.{ }^{2}\right)$ & $2.1 \pm 0.5$ & $2.2 \pm 0.4$ & $2.1 \pm 0.6$ & 0.442 \\
Hypertension & $26(33.3 \%)$ & $22(34.4 \%)$ & $4(28.6 \%)$ & 0.677 \\
Diabetes & $13(16.7 \%)$ & $11(17.2 \%)$ & $2(14.3 \%)$ & 0.792 \\
Smoking & $5(6.4 \%)$ & $5(7.8 \%)$ & $0(0 \%)$ & 0.506 \\
CKD & $5(6.4 \%)$ & $4(6.3 \%)$ & $1(7.1 \%)$ & 0.902 \\
CAD & $1(1.3 \%)$ & $1(1.6 \%)$ & $0(0 \%)$ & 0.819 \\
Previous MI & $3(3.8 \%)$ & $3(4.7 \%)$ & $0(0 \%)$ & 0.744 \\
HF & $3(3.8 \%)$ & $3(4.7 \%)$ & $8.6 \pm 2.9$ & 0.744 \\
SOFA & $8.5 \pm 3.2$ & $8.4 \pm 3.3$ & $32.9 \pm 12.6$ & 0.834 \\
SAPS II & $35.3 \pm 11.0$ & $35.8 \pm 10.7$ & $16.6 \pm 6.8$ & 0.375 \\
APACHE II & $14.4 \pm 6.6$ & $13.9 \pm 6.5$ & 0.165 \\
\hline VPC
\end{tabular}

$\mathrm{V}-\mathrm{V}$, veno-venous; ECMO, extracorporeal membrane oxygenation; BMI, body mass index; BSA, body surface area; CKD, chronic kidney disease; CAD, coronary artery disease; MI, myocardial infarction; HF, heart failure; SOFA, Sequential Organ Failure Assessment; SAPS II, Simplified Acute Physiology Score II; and APACHE II, Acute Physiology And Chronic Health Evaluation II. 
Table 2. On-ECMO characteristics.

\begin{tabular}{|c|c|c|c|c|}
\hline Variable & Total (78) & V-V ECMO (64) & ECMO Conversion (14) & $p$ Value \\
\hline Off-site implant & $57(73.1 \%)$ & $49(76.6 \%)$ & $8(51.7 \%)$ & 0.141 \\
\hline ECMO duration $(\mathrm{d})$ & $16.5 \pm 10.0$ & $16.4 \pm 9.4$ & $17.8 \pm 10.5$ & 0.621 \\
\hline ICU duration $(\mathrm{d})$ & $22.3 \pm 11.4$ & $23.0 \pm 11.3$ & $22.4 \pm 12.3$ & 0.859 \\
\hline HLoS before ICU & $6.2 \pm 5.9$ & $5.9 \pm 5.8$ & $6.6 \pm 5.2$ & 0.677 \\
\hline $\mathrm{FiO}_{2}(24 \mathrm{~h})$ & $95.1 \pm 8.3$ & $95.4 \pm 7.6$ & $93.0 \pm 15.3$ & 0.385 \\
\hline $\mathrm{pH}(24 \mathrm{~h})$ & $7.4 \pm 0.1$ & $7.4 \pm 0.1$ & $7.2 \pm 1.1$ & 0.143 \\
\hline $\mathrm{paO}_{2}(24 \mathrm{~h})$ & $60.2 \pm 19.3$ & $61.1 \pm 20.1$ & $58.5 \pm 21.5$ & 0.665 \\
\hline $\mathrm{paCO}_{2}(24 \mathrm{~h})$ & $58.8 \pm 20.5$ & $58.5 \pm 20.7$ & $59.1 \pm 22.0$ & 0.923 \\
\hline $\mathrm{SpO}_{2}(24 \mathrm{~h})$ & $86.4 \pm 9.3$ & $86.4 \pm 9.7$ & $83.9 \pm 15.8$ & 0.440 \\
\hline $\mathrm{PaO}_{2} / \mathrm{FiO}_{2}(24 \mathrm{~h})$ & $64.1 \pm 22.8$ & $64.8 \pm 23.3$ & $62.5 \pm 24.3$ & 0.740 \\
\hline CK $(24 \mathrm{~h})$ & $148(68-524)$ & $148(70-524)$ & $158(63-362)$ & 0.292 \\
\hline CK-MB (24 h) & $26(17-45)$ & $28(18-55)$ & $21(17-27)$ & 0.430 \\
\hline $\operatorname{TnI}(24 \mathrm{~h})$ & $60(24.5-202.9)$ & $75(25-220)$ & $52.8(26.45-173.3)$ & 0.436 \\
\hline proBNP (24 h) & $535(245-3105)$ & 395 (184-1855) & $909(478-6354)$ & 0.209 \\
\hline AST $(24$ h) & $42(28-75)$ & $46(30-85)$ & $33(28-39)$ & 0.194 \\
\hline ALT (24 h) & $52(30-98)$ & $54(32-99)$ & $36(26-55)$ & 0.155 \\
\hline LDH (24 h) & $468(344-908)$ & $486(338-1295)$ & 455 (375-603) & 0.196 \\
\hline Lactate $(24 \mathrm{~h})$ & $1.6(1.2-2.1)$ & $1.5(1.1-2.1)$ & $1.8(1.2-2.0)$ & 0.560 \\
\hline Ferritin $(24 \mathrm{~h})$ & $1852(1426-2817)$ & $1808(1426-3200)$ & 1878 (1599-2053) & 0.203 \\
\hline IL-6 & $161(49-2195)$ & $185(48-2626)$ & $129(53-488)$ & 0.260 \\
\hline PT & $13.4(12.7-14.9)$ & $13.3(12.7-14.9)$ & $13.4(12.7-15.1)$ & 0.373 \\
\hline APTT & $38.1(33.1-47.4)$ & $38.1(33.1-46.1)$ & $37.2(32.9-59.2)$ & 0.165 \\
\hline Fibrinogen & $508(320-707)$ & $516(334-720)$ & $406(280-629)$ & 0.688 \\
\hline D-dimer & $4660(2023-12,810)$ & $4550(2095-15,931)$ & 4771 (1754-5403) & 0.758 \\
\hline CRP & $125.8(61.1-194.1)$ & $126.6(60.5-216.8)$ & $114.1(87.8-165.1)$ & 0.589 \\
\hline PCT & $0.7(0.2-1.9)$ & $0.8(0.2-1.9)$ & $0.3(0.2-0.8)$ & 0.519 \\
\hline $\mathrm{Hb}$ & $10.9(9.8-12.1)$ & $10.9(9.9-12.5)$ & $10.7(9.6-11.1)$ & 0.274 \\
\hline Dobutamine & $12(15.4 \%)$ & $7(10.9 \%)$ & $5(35.7 \%)$ & 0.023 \\
\hline Dopamine & $3(3.8 \%)$ & $2(3.1 \%)$ & $1(7.1 \%)$ & 0.486 \\
\hline Adrenaline & $13(16.7 \%)$ & $11(17.2 \%)$ & $2(14.3 \%)$ & 0.792 \\
\hline Noradrenaline & $74(94.9 \%)$ & $60(98.3 \%)$ & $14(100 \%)$ & 0.610 \\
\hline Atropine & $5(6.4 \%)$ & $4(6.3 \%)$ & $1(7.1 \%)$ & 0.902 \\
\hline Levosimendan & $1(1.3 \%)$ & $1(1.6 \%)$ & $0(0 \%)$ & 0.819 \\
\hline HR & $83.2 \pm 24.6$ & $82.8 \pm 21.6$ & $83.5 \pm 25.8$ & 0.916 \\
\hline MAP & $82.0 \pm 16.1$ & $83.6 \pm 12.4$ & $80.7 \pm 19.3$ & 0.477 \\
\hline
\end{tabular}

$\mathrm{ECMO}$, extracorporeal membrane oxygenation; $\mathrm{ICU}$, intensive care unit; $\mathrm{HLoS}$, hospital length of stay; $\mathrm{FiO}_{2}$, fraction of inspired oxygen; CK, creatinine kinase; MB, muscle-brain; TnI; I troponin; BNP, brain natriuretic peptide; AST, aspartate transaminase; ALT, alanine aminotransferase; LDH, lactate dehydrogenase; IL, interleukin; PT, prothrombin time; APTT, activated partial thromboplastin time; CRP, c-reactive protein; $\mathrm{PCT}$, procalcitonin; $\mathrm{Hb}$, haemoglobin; $\mathrm{HR}$, heart rate; and MAP, mean arterial pressure. Numbers in parentheses are percentage or interquartile ranges where applicable.

\section{Clinical Outcomes}

Nineteen patients (24.4\%) survived to discharge or lung transplantation; the 30-day mortality was higher in patients who underwent conversion to more advanced ECMO configurations (Figure 2) (Log-rank $p=0.029$ ). Table 3 lists the complications occurring during ECMO therapy. Major bleeding was most common complication (67.9\%), followed by sepsis $(42.3 \%)$, continuous veno-venous hemofiltration $(30.8 \%)$ and multiorgan failure (20.5\%). In patients who did not undergo conversion, the odds of cardiovascular complications (OR [95\% CIs]: 0.16 [0.05-0.58]; $p=0.005$ ), limb complications (OR [95\% CIs]: 0.06 [0.01-0.61]; $p=0.018$ ) and circuit complications (OR [95\% CIs]: 0.04 [0.00-0.86]; $p=0.040$ ) were significantly lower compared with those transitioned to modified forms of support. 


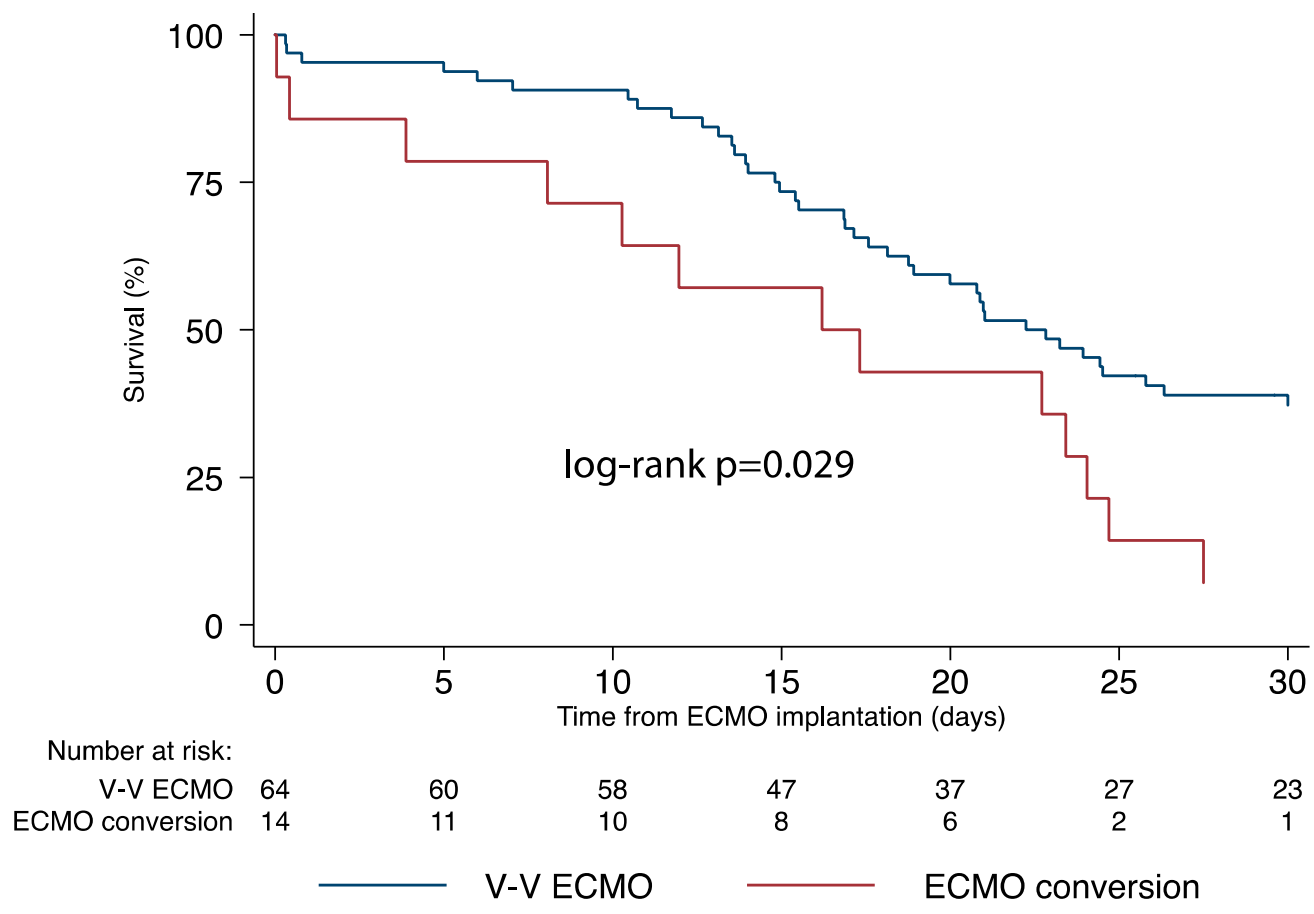

Figure 2. Survival comparison between veno-venous ECMO and more advanced ECMO support configuration forms. ECMO, extracorporeal membrane oxygenation.

Table 3. Complications.

\begin{tabular}{cccccc}
\hline Variable & Total (78) & V-V ECMO (64) & ECMO Conversion (14) & ORs (95\% CIs) & $p$ Value \\
\hline Major bleeding & $53(67.9 \%)$ & $45(70.3 \%)$ & $8(57.1 \%)$ & $1.78(0.54-5.82)$ & 0.343 \\
Massive transfusions & $7(9.0 \%)$ & $7(10.9 \%)$ & $0(0 \%)$ & $3.78(0.2-70.14)$ & 0.372 \\
Circuit complications & $2(2.6 \%)$ & $0(0 \%)$ & $2(14.3 \%)$ & $0.04(0.00-0.86)$ & 0.040 \\
Stroke & $5(6.4 \%)$ & $4(6.3 \%)$ & $1(7.1 \%)$ & $0.87(0.09-8.40)$ & 0.902 \\
CVVH & $24(30.8 \%)$ & $17(26.6 \%)$ & $7(50.0 \%)$ & $0.36(0.11-1.18)$ & 0.093 \\
Cardiovascular & $16(20.5 \%)$ & $9(14.1 \%)$ & $7(50.0 \%)$ & $0.16(0.05-0.58)$ & 0.005 \\
Pulmonary & $14(17.9 \%)$ & $11(17.2 \%)$ & $3(21.4 \%)$ & $0.76(0.18-3.19)$ & 0.709 \\
Metabolic & $7(9.0 \%)$ & $5(7.8 \%)$ & $2(14.3 \%)$ & $0.51(0.09-2.94)$ & 0.450 \\
Limb & $4(5.1 \%)$ & $1(1.6 \%)$ & $3(21.4 \%)$ & $0.06(0.01-0.61)$ & 0.018 \\
Sepsis & $33(42.3 \%)$ & $28(43.8 \%)$ & $5(35.7 \%)$ & $1.40(0.42-4.65)$ & 0.582 \\
MOF & $16(20.5 \%)$ & $12(18.8 \%)$ & $4(28.6 \%)$ & $0.58(0.15-2.16)$ & 0.414 \\
\hline
\end{tabular}

ECMO, extracorporeal membrane oxygenation, $\mathrm{CVVH}$, continuous veno-venous hemofiltration; $\mathrm{MOF}$, multiorgan failure; OR, odds ratio; and $\mathrm{CI}$, confidence interval.

\section{Discussion}

The current study reports the characteristics and outcomes of COVID-19 patients requiring V-V ECMO and the subsequent conversion to other ECMO configurations in a single high-volume COVID-19 hub in Poland. Seventy-eight COVID-19 patients required V-V ECMO for ARDS from March 2020 to May 2021. In 18\% of them, ECMO conversion was performed for inadequate drainage, inadequate perfusion, AMI, hypovolemic shock, cardiogenic shock or septic shock. Patients requiring subsequent conversion more often were treated with dobutamine already in the first $24 \mathrm{~h}$ of V-V ECMO support. Among the ECMO settings chosen for conversion, cardio-circulatory support was required in $64 \%$ of cases and was associated with a $100 \%$ mortality. Predictors for conversion to a different ECMO configuration were dobutamine use and a shorter ICU time. Overall, mortality and complications were significantly higher in the conversion group.

Extracorporeal membrane oxygenation is a technology that can help critically ill patients who have failed to respond to traditional care by supporting their weakened cardiovascular and pulmonary systems individually or in combination [16-23]. ECMO 
is typically used in the setting of isolated respiratory failure due to refractory ARDS [24]. Since March 2020 and the beginning of the SARS-CoV-2 pandemic, V-V ECMO has also become a treatment tool for critically ill patients diagnosed with COVID-19-induced ARRF.

Indeed, ECMO may be indicated in COVID-19 patients with extreme pneumonia and acute respiratory compromise who have failed to respond to standard treatment options such as pronation, standard lung protective ventilation techniques, volume optimization and neuromuscular blockade $[21,25,26]$. In the case of $\mathrm{PaO} 2 / \mathrm{FiO} 2<100 \mathrm{~mm} \mathrm{Hg}$ and/or arterial blood $\mathrm{pH}<7.2$ and $\mathrm{PaCO} 2>60 \mathrm{~mm} \mathrm{Hg}$, ECMO is indicated [4]. Early V-V ECMO implantation in respiratory distress was shown to reduce respiratory-driven pressure, reduce pulmonary and systemic inflammation and improve extreme multi-organ system dysfunction $[27,28]$. This demonstrates the usefulness of V-V ECMO in COVID-19 patients.

It is increasingly recognized, however, that some COVID-19 patients already treated for ARRF, may also develop combined cardiac involvement and circulatory compromise. Indeed, up to 20-25\% of COVID-19 patients develop some degree of cardiovascular damage, which adversely affects their prognosis [10-12]. It has been demonstrated that COVID19 patients can develop myocardial injury through direct cardiotoxicity, microvascular thrombosis and endothelial injury, pulmonary embolism, immune dysregulation, and myocarditis and myocardial infarction type 1 or 2 [10].

The above-mentioned conditions may, in turn, necessitate modification of the ECMO support, requiring the implantation of veno-arterial (V-A) ECMO or other ECMO modalities for primary or combined cardio-circulatory support [29,30]. Furthermore, hypovolemic or septic shock may also occur in these patients with the consequent need for adjustment of the primary ECMO configuration [11]. Finally, other circumstances, such as access- or site-related complications, differential oxygenation or vascular site bleeding, can necessitate a change in ECMO configuration by inserting an additional cannula(s), to respond to the patient's metabolic needs and oxygenation by increasing the drainage and perfusion flow.

Nevertheless, reports on ECMO configuration changes in COVID-19 patients are lacking and no clear indications exist to early identify patients at risk of ECMO conversion due to worsening of their clinical situation. It is not clear if an early conversion or the use of advanced ECMO configurations (Figure 3 ) since the very beginning might help to improve the survival of these patients.

The current report, to our knowledge, is the first to address ECMO configuration changes during treatment of COVID-19 induced ARDS. Based on our experience, the need for ECMO conversion may occur in as many as $18 \%$ of V-V ECMO patients. In this population, circulatory support is required in up to $64 \%$ of patients, while the remaining cases might benefit from additional venous cannulations to improve the blood return or perfusion in respiratory support. Contrarily, the available literature reports a much lower percentage of ECMO configuration conversions ranging from $2 \%$ to $7 \%$ [31-36]. This difference might be explained with the different policies applied in ECMO centres all over the world.

The use of advanced ECMO configurations and the practice of ECMO configuration changes are generally considered high-risk procedures, burdened with high mortality and complication risks. It is, therefore, understandable that many centres still consider this practice as the last possible choice for very complicated patients, and they refrain from using it when considered futile. Moreover, the COVID-19 pandemic has raised the important problem of resource allocation, which might have pushed many centres to avoid the use of complex ECMO configurations in patients with predicted poor outcomes [37]. It is, thus, possible to hypothesize that there could have been many more COVID-19 patients requiring an ECMO configuration change compared with those who actually received this treatment based on the abovementioned reasons. 


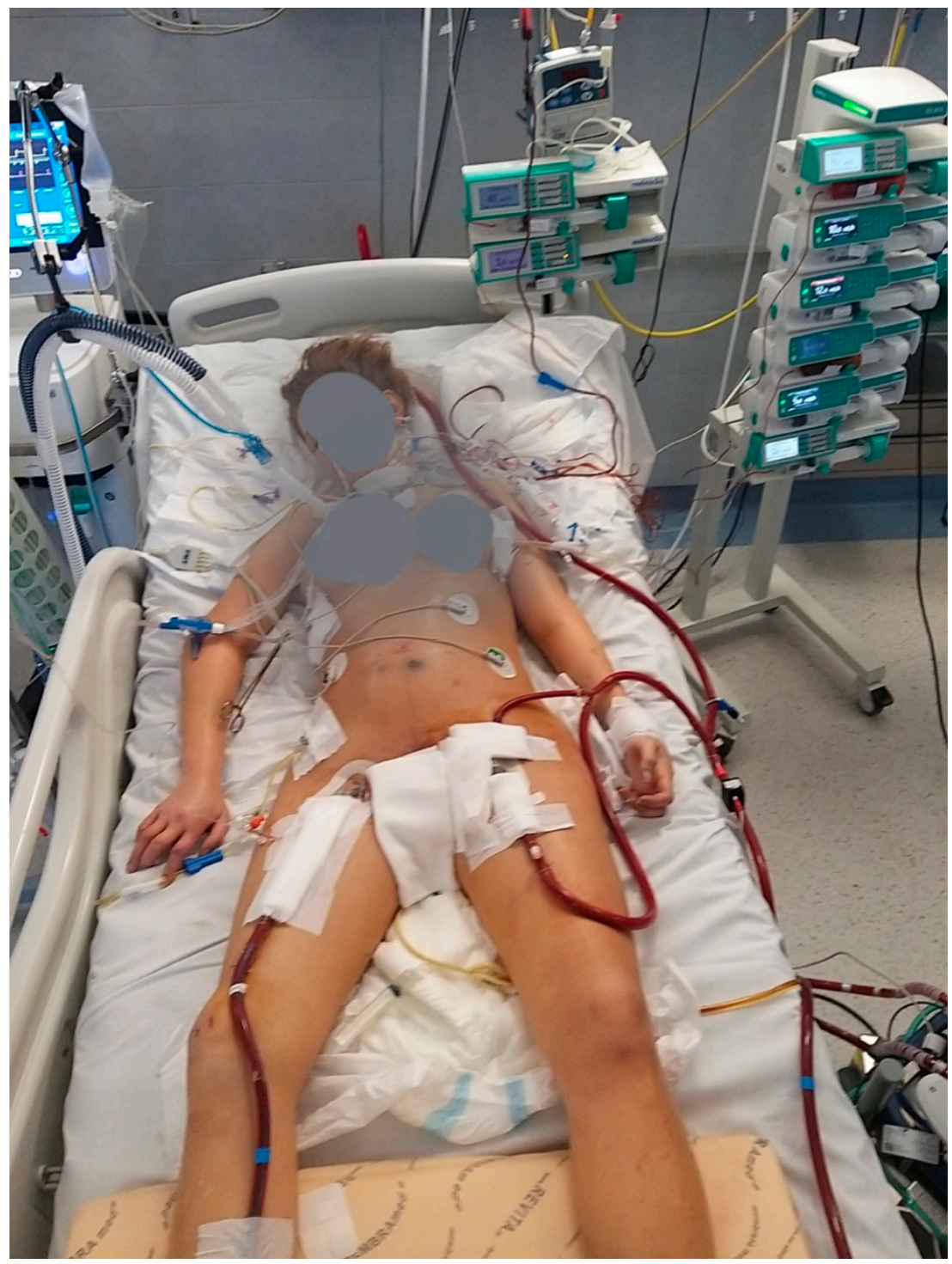

Figure 3. Hybrid ECMO setting for COVID-19 ARRF. V-VA (+) configuration: venous drainage femoral cannula, venous inflow jugular cannula, arterial femoral cannula and (+): femoral distal perfusion cannula.

The alarming mortality rates that we observed in this study confirm the poor outcomes of these patients. Indeed, only one patient survived (7\%) among those who underwent ECMO conversion with a significant 30-day higher mortality in the conversion group $(p=0.029)$. Moreover, complications were significantly more frequent after ECMO configuration changes; in fact, the odds of cardiovascular complications, limb complications and circuit complications were much lower in patients requiring only V-V ECMO. This can be explained considering the underlying status of the patients and the higher complexity of the ECMO circuit, irrespective of the indications to the modifications.

Undeniably, the risk of complications is associated with the number of cannulation sites, which are multiple in the hybrid ECMO configurations. Moreover, a considerable number of patients requiring additional drainage cannula may reflect the large extent of lung involvement and marginal oxygenation as the expression of a more advanced ARDS status. This status can manifest also with a greater extent of the inflammatory response and cytokine storm, which is a well-described process in COVID-19 patients [38].

On the other hand, the question to be asked is if these outcomes could be improved through an early identification of patients at risk and an early initiation of V-A or hybrid 
ECMO configurations. The reasons for conversion observed in this study were multifactorial and included inadequate drainage, inadequate perfusion and myocardial infarction followed by hypovolemic-, cardiogenic- and septic shock. As previously discussed, the cardiac involvement in COVID-19 has been highlighted in several studies although it is still partially underestimated in clinical practice as reflected by the recent guidelines [39].

We observed that patients requiring subsequent conversion were treated more often with dobutamine in the first hours of V-V ECMO support. Dobutamine is rarely used as the first inotropic and vasoconstrictive agent in such scenarios. Conversely, this may reflect the deteriorating patient status who may, at this time, require two or three agents to maintain proper organ perfusion. Moreover, median pro-BNP values during the first $24 \mathrm{~h}$ were $395 \mathrm{pg} / \mathrm{mL}$ (IQR: 184-1855) in the V-V ECMO group and $909 \mathrm{pg} / \mathrm{mL}$ (IQR: 478-6354) in the conversion group but with no significant differences $(p=0.209)$. We could not establish any other single reliable factor that would predict the need to convert a patient in the course of ECMO treatment to a more advanced form of support based on pre-COVID variables and/or initial ECMO laboratory values.

To better account for the inherent differences between patients necessitating a transition to arterial ECMO modes (V-A, V-VA, VV-AV etc.) for predominantly cardiocirculatory collapse rather than just inadequate drainage $(\mathrm{V}-\mathrm{VV})$, we conducted uni/multivariable analyses again focusing only on the earlier group. The above findings can be explained, only partially, by the small sample size. In fact, ECMO is a dynamic process and so are the changes in pulmonary and cardiovascular systems during COVID-19 [40]. Further studies with larger cohorts of patients are, thus, required to investigate this topic and identify the predictors for ECMO configuration changes.

\section{Limitations}

Certain limitations to the current analysis need to be acknowledged. First of all, this is a retrospective analysis that included patients infected with SARS-CoV-2 during the first, second and third wave of the pandemic. Therefore, we cannot exclude an effect of different viral penetration and different concomitant therapies on mortality and disease severity. In fact, in another study, we reported higher mortality rates with COVID ECMO in the second and third wave of the pandemic as compared to the first wave [13].

The above may be attributable, in part, to novel strains of COVID-19, in particular B1.1.7 "Kent" variant, leading to higher infection rates, more severe manifestation and more COVID-19 hospitalizations and deaths among younger individuals. Moreover, several patients received V-V ECMO implantation in peripheral hospitals and were subsequently transferred to our centre, potentially increasing the risks of complications related to the transport of unstable patients. This might have pushed some clinicians to start ECMO support with the simpler V-V configuration and later switch to more complex but necessary hybrid ECMO settings.

Additionally, selection bias arising from the paucity of ECMO devices in the peak of the third wave as well as selection bias due to the learning curve and switching to hybrid cannulation earlier in the more recent phase cannot be excluded but is subject to another ongoing investigation. In addition, certain clinical variables e.g., time from positive testing to ECMO or the left ventricle ejection fraction are largely missing. Finally, patients who underwent multiple ECMO runs and direct V-A or hybrid ECMO support were excluded from this analysis. We cannot exclude a lower mortality in these groups and a broader analysis is required to address this question.

\section{Conclusions}

As many as $18 \%$ of patients undergoing V-V ECMO for COVID-19 ARRF may require conversion to V-A or more advanced ECMO support with a high mortality and complication rate. Veno-arterial and hybrid configurations can answer the immediate needs of a patient with concurrent cardiocirculatory collapse or inadequate venous drainage. 
Early recognition and treatment of such conditions needs to be further investigated to improve the outcomes in such complex patients.

Author Contributions: Conceptualization, M.K. and P.S.; methodology, M.K.; software, M.K.; validation, P.S., J.S, J.B., M.B., S.M., D.D., K.S., R.S., M.F., W.S., A.G., A.W., W.W., A.Z., Z.K., E.O., M.P., J.M.R., M.E.d.P., R.L., M.K.; formal analysis, M.K.; investigation, M.K., J.S., S.M. and J.M.R.; resources, S.M.; data curation, J.B. and M.B.; writing-original draft preparation, M.K. and S.M.; writing-review and editing, M.K. and P.S.; visualization, M.K.; supervision, M.K., R.L. and P.S.; project administration, P.S.; funding acquisition, N/A. All authors have read and agreed to the published version of the manuscript.

Funding: This research received no external funding.

Institutional Review Board Statement: The study was conducted according to the guidelines of the Declaration of Helsinki and approved by the Institutional Review Board of Central Clinical Hospital of Ministry of Interior (protocol code: CSKMSWiA 2021/20; date of approval 10 May 2021).

Informed Consent Statement: This study was approved by the Institutional Review Board but patient consent for inclusion in the registry was waived.

Data Availability Statement: Data are available upon request.

Conflicts of Interest: The authors declare no conflict of interest.

\section{Appendix A}

Table A1. Univariable and multivariable analysis. Predictors of ECMO conversion.

\begin{tabular}{|c|c|c|c|c|}
\hline \multirow{2}{*}{ Variable } & \multicolumn{2}{|c|}{ Univariable } & \multicolumn{2}{|c|}{ Multivariable } \\
\hline & OR (95\% CIs) & $p$ Value & OR (95\% CIs) & $p$ Value \\
\hline Age & $0.95(0.88-1.02)$ & 0.132 & $0.93(0.85-1.03)$ & 0.169 \\
\hline Female & $0.73(0.14-3.82)$ & 0.712 & - & - \\
\hline BMI $\left(\mathrm{kg} / \mathrm{m}^{2}\right)$ & $0.88(0.26-3.04)$ & 0.845 & - & - \\
\hline $\mathrm{BSA}\left(\mathrm{m}^{2}\right)$ & $0.00\left(1.15 \times 10^{-24}-3.67 \times 10^{18}\right)$ & 0.804 & - & - \\
\hline Hypertension & $0.85(0.17-4.18)$ & 0.841 & - & - \\
\hline Diabetes & $1.50(0.18-12.44)$ & 0.705 & - & - \\
\hline CKD & $0.97(0.06-16.81)$ & 0.984 & - & - \\
\hline SOFA & $1.02(0.84-1.23)$ & 0.841 & - & - \\
\hline SAPS II & $0.97(0.91-1.04)$ & 0.400 & - & - \\
\hline APACHE II & $1.06(0.97-1.16)$ & 0.184 & $1.05(0.91-1.21)$ & 0.490 \\
\hline Off-site implant & $0.56(0.12-2.63)$ & 0.462 & - & - \\
\hline ICU duration (d) & $0.95(0.89-1.02)$ & 0.176 & $0.90(0.82-0.99)$ & 0.047 \\
\hline HLoS before ICU & $1.03(0.94-1.15)$ & 0.456 & - & - \\
\hline $\mathrm{FiO}_{2}(24 \mathrm{~h})$ & $1.29(0.74-2.27)$ & 0.365 & - & - \\
\hline $\mathrm{pH}(24 \mathrm{~h})$ & $4.51\left(0.00-9.26 \times 10^{5}\right)$ & 0.809 & - & - \\
\hline $\mathrm{paO}_{2}(24 \mathrm{~h})$ & $0.74(0.36-1.50)$ & 0.401 & - & - \\
\hline $\mathrm{paCO}_{2}(24 \mathrm{~h})$ & $1.02(0.95-1.10)$ & 0.542 & - & - \\
\hline $\mathrm{SpO}_{2}(24 \mathrm{~h})$ & $1.06(0.92-1.23)$ & 0.402 & - & - \\
\hline $\mathrm{PaO}_{2} / \mathrm{FiO}_{2}(24 \mathrm{~h})$ & $1.26(0.66-2.41)$ & 0.478 & - & - \\
\hline CK & $0.96(0.84-1.10)$ & 0.556 & - & - \\
\hline CK-MB & $1.05(0.74-1.48)$ & 0.787 & - & - \\
\hline $\mathrm{TnI}$ & $1.00(0.99-1.01)$ & 0.947 & - & - \\
\hline proBNP & $1.00(1.00-1.01)$ & 0.263 & - & - \\
\hline AST & $0.99(0.98-1.01)$ & 0.606 & - & - \\
\hline ALT & $0.99(0.98-1.01)$ & 0.418 & - & - \\
\hline LDH & $1.00(0.99-1.01)$ & 0.362 & - & - \\
\hline Lactate & $0.89(0.01-113.28)$ & 0.964 & - & - \\
\hline Ferritin & $1.00(0.99-1.01)$ & 0.729 & - & - \\
\hline IL-6 & $1.00(1.00-1.01)$ & 0.399 & - & - \\
\hline
\end{tabular}


Table A1. Cont.

\begin{tabular}{|c|c|c|c|c|}
\hline \multirow{2}{*}{ Variable } & \multicolumn{2}{|c|}{ Univariable } & \multicolumn{2}{|c|}{ Multivariable } \\
\hline & OR (95\% CIs) & $p$ Value & OR (95\% CIs) & $p$ Value \\
\hline $\mathrm{PT}$ & $0.90(0.70-1.17)$ & 0.440 & - & - \\
\hline APTT & $1.01(0.99-1.03)$ & 0.164 & $1.02(0.99-1.05)$ & 0.149 \\
\hline Fibrinogen & $0.99(0.99-1.00)$ & 0.524 & - & - \\
\hline D-dimer & $1.00(0.99-1.00)$ & 0.389 & - & - \\
\hline CRP & $0.99(0.98-1.01)$ & 0.748 & - & - \\
\hline PCT & $0.99(0.94-1.06)$ & 0.932 & - & - \\
\hline $\mathrm{Hb}$ & $0.66(0.39-1.21)$ & 0.193 & $0.59(0.32-1.10)$ & 0.098 \\
\hline Dobutamine & $4.94(0.80-30.60)$ & 0.086 & $14.70(2.11-102.20)$ & 0.007 \\
\hline Dopamine & $4.76(0.15-153.17)$ & 0.378 & - & - \\
\hline Adrenaline & $1.62(0.21-12.48)$ & 0.645 & - & - \\
\hline Atropine & $1.01(0.06-17.25)$ & 0.996 & - & - \\
\hline HR & $1.02(0.99-1.05)$ & 0.147 & $1.03(0.99-1.06)$ & 0.086 \\
\hline MAP & $0.97(0.92-1.02)$ & 0.208 & - & - \\
\hline
\end{tabular}

Variables that presented collinearity are not presented. ECMO, extracorporeal membrane oxygenation; OR, odds ratio; CI, confidence interval; BMI, body mass index; chronic kidney disease; SOFA, Sequential Organ Failure Assessment; SAPS II, Simplified Acute Physiology Score II; APACHE II, Acute Physiology And Chronic Health Evaluation II; ICU, intensive care unit; HLoS, hospital length of stay; $\mathrm{FiO}_{2}$, fraction of inspired oxygen; CK, creatinine kinase; MB, muscle-brain; TnI; I troponin; BNP, brain natriuretic peptide; AST, aspartate transaminase; ALT, alanine aminotransferase; LDH, lactate dehydrogenase; IL, interleukin; PT, prothrombin time; APTT, activated partial thromboplastin time; $\mathrm{CRP}$, c-reactive protein; $\mathrm{PCT}$, procalcitonin; $\mathrm{Hb}$, hemoglobin; $\mathrm{HR}$, heart rate; and MAP, mean arterial pressure.

\section{References}

1. Lorusso, R.; Combes, A.; Coco, V.L.; De Piero, M.E.; Belohlavek, J. ECMO for COVID-19 patients in Europe and Israel. Intensiv. Care Med. 2021, 47, 344-348. [CrossRef]

2. Barbaro, R.P.; MacLaren, G.; Boonstra, P.S.; Iwashyna, T.J.; Slutsky, A.S.; Fan, E.; Bartlett, R.H.; Tonna, J.E.; Hyslop, R.; Fanning, J.J.; et al. Extracorporeal membrane oxygenation support in COVID-19: An international cohort study of the Extracorporeal Life Support Organization registry. Lancet 2020, 396, 1071-1078. [CrossRef]

3. Peek, G.J.; Mugford, M.; Tiruvoipati, R.; Wilson, A.; Allen, E.; Thalanany, M.M.; Hibbert, C.L.; Truesdale, A.; Clemens, F.; Cooper, N.; et al. Efficacy and economic assessment of conventional ventilatory support versus extracorporeal membrane oxygenation for severe adult respiratory failure (CESAR): A multicentre randomised controlled trial. Lancet 2009, 374, 1351-1363. [CrossRef]

4. Combes, A.; Hajage, D.; Capellier, G.; Demoule, A.; Lavoué, S.; Guervilly, C.; Da Silva, D.; Zafrani, L.; Tirot, P.; Veber, B.; et al. Extracorporeal Membrane Oxygenation for Severe Acute Respiratory Distress Syndrome. N. Engl. J. Med. 2018, 378, 1965-1975. [CrossRef]

5. Coco, V.L.; Swol, J.; De Piero, M.E.; Massimi, G.; Chiarini, G.; Broman, L.M.; Lorusso, R. Dynamic extracorporeal life support: A novel management modality in temporary cardio-circulatory assistance. Artif. Organs 2021, 45, 427-434. [CrossRef] [PubMed]

6. De Piero, M.E.; Coco, V.L.; Taccone, F.S.; Belliato, M.; Broman, L.M.; Malfertheiner, M.V.; Lorusso, R. Has Venoarterial ECMO Been Underutilized in COVID-19 Patients? Innov. Technol. Tech. Cardiothorac. Vasc. Surg. 2020, 15, 317-321. [CrossRef]

7. Anderson, H.L.; Delius, R.E.; Sinard, J.M.; McCurry, K.R.; Shanley, C.J.; Chapman, R.A.; Shapiro, M.B.; Rodriguez, J.L.; Bartlett, R.H. Early experience with adult extracorporeal membrane oxygenation in the modern era. Ann. Thorac. Surg. 1992, 53, 553-563. [CrossRef]

8. Kolla, S.; Awad, S.S.; Rich, P.B.; Schreiner, R.J.; Hirschl, R.B.; Bartlett, R.H. Extracorporeal Life Support for 100 Adult Patients with Severe Respiratory Failure. Ann. Surg. 1997, 226, 544-566. [CrossRef]

9. Hemmila, M.R.; Rowe, S.A.; Boules, T.N.; Miskulin, J.; McGillicuddy, J.W.; Schuerer, D.J.; Haft, J.W.; Swaniker, F.; Arbabi, S.; Hirschl, R.B.; et al. Extracorporeal Life Support for Severe Acute Respiratory Distress Syndrome in Adults. Ann. Surg. 2004, 240, 595-607. [CrossRef]

10. Guzik, T.J.; Mohiddin, S.A.; DiMarco, A.; Patel, V.; Savvatis, K.; Marelli-Berg, F.M.; Madhur, M.S.; Tomaszewski, M.; Maffia, P.; D'Acquisto, F; ; et al. COVID-19 and the cardiovascular system: Implications for risk assessment, diagnosis, and treatment options. Cardiovasc. Res. 2020, 116, 1666-1687. [CrossRef]

11. Wang, D.; Hu, B.; Hu, C.; Zhu, F.; Liu, X.; Zhang, J.; Wang, B.; Xiang, H.; Cheng, Z.; Xiong, Y.; et al. Clinical characteristics of 138 hospitalized patients with 2019 novel coronavirus-infected pneumonia in Wuhan, China. JAMA 2020, 323, 1061-1069. [CrossRef] [PubMed]

12. Kunutsor, S.K.; Laukkanen, J.A. Cardiovascular complications in COVID-19: A systematic review and meta-analysis. J. Infect. 2020, 81, e139-e141. [CrossRef]

13. Suwalski, P.; Drobiński, D.; Smoczyński, R.; Franczyk, M.; Sarnowski, W.; Gajewska, A.; Witkowska, A.; Wierzba, W.; Zaczyński, A.; Król, Z.; et al. Analysis of 75 consecutive COVID-19 ECMO cases in Warsaw Centre for Extracorporeal Therapies. Kardiologia Polska 2021. [CrossRef] [PubMed] 
14. Polish Diagnostic, Therapeutic and Organizational Recommendations for the Care of Individuals Infected with SARS-CoV-2 or Exposed to a SARS-CoV-2 Infection. Available online: https://www.aotm.gov.pl/media/2020/07/Covid_FINAL-v-1.1-_wersjaEN-1.pdf (accessed on 1 June 2021).

15. Extracorporeal Life Support Organization SARS-CoV-2 Registry Addendum Database Definitions. 2020. Available online: https:/ / www.elso.org/Registry/DataDefinitions,Forms, Instructions.aspx (accessed on 1 June 2021).

16. Fraser, J.F.; Shekar, K.; Diab, S.; Dunster, K.; Foley, S.R.; McDonald, C.I.; Passmore, M.; Šimonová, G.; Roberts, J.A.; Platts, D.G.; et al. ECMO-The clinician's view. ISBT Sci. Ser. 2012, 7, 82-88. [CrossRef]

17. Shekar, K.; Mullany, D.V.; Thomson, B.; Ziegenfuss, M.; Platts, D.G.; Fraser, J.F. Extracorporeal life support devices and strategies for management of acute cardiorespiratory failure in adult patients: A comprehensive review. Crit. Care 2014, 18, 219. [CrossRef] [PubMed]

18. Peck, T.J.; Hibbert, K. Recent advances in the understanding and management of ARDS. F1000Research 2019, 8, 1959. [CrossRef] [PubMed]

19. Goligher, E.C.; Tomlinson, G.; Hajage, D.; Wijeysundera, D.N.; Fan, E.; Jüni, P.; Brodie, D.; Slutsky, A.S.; Combes, A. Extracorporeal Membrane Oxygenation for Severe Acute Respiratory Distress Syndrome and Posterior Probability of Mortality Benefit in a Post Hoc Bayesian Analysis of a Randomized Clinical Trial. JAMA 2018, 320, 2251-2259. [CrossRef]

20. Munshi, L.; Walkey, A.; Goligher, E.; Pham, T.; Uleryk, E.M.; Fan, E. Venovenous extracorporeal membrane oxygenation for acute respiratory distress syndrome: A systematic review and meta-analysis. Lancet Respir. Med. 2019, 7, 163-172. [CrossRef]

21. Abrams, D.; Ferguson, N.; Brochard, L.; Fan, E.; Mercat, A.; Combes, A.; Pellegrino, V.; Schmidt, M.; Slutsky, A.S.; Brodie, D. ECMO for ARDS: From salvage to standard of care? Lancet Respir. Med. 2019, 7, 108-110. [CrossRef]

22. Squiers, J.J.; Lima, B.; DiMaio, J.M. Contemporary extracorporeal membrane oxygenation therapy in adults: Fundamental principles and systematic review of the evidence. J. Thorac. Cardiovasc. Surg. 2016, 152, 20-32. [CrossRef]

23. Ware, L.B.; Matthay, M.A. The Acute Respiratory Distress Syndrome. N. Engl. J. Med. 2000, 342, 1334-1349. [CrossRef]

24. Esan, A.; Hess, D.R.; Raoof, S.; George, L.; Sessler, C.N. Severe Hypoxemic Respiratory Failure: Part 1-Ventilatory strategies. Chest 2010, 137, 1203-1216. [CrossRef]

25. Fan, E.; Del Sorbo, L.; Goligher, E.C.; Hodgson, C.L.; Munshi, L.; Walkey, A.J.; Adhikari, N.K.; Amato, M.B.; Branson, R.; Brower, R.G.; et al. An Official American Thoracic Society/European Society of Intensive Care Medicine/Society of Critical Care Medicine Clinical Practice Guideline: Mechanical Ventilation in Adult Patients with Acute Respiratory Distress Syndrome. Am. J. Respir. Crit. Care Med. 2017, 195, 1253-1263. [CrossRef] [PubMed]

26. Abrams, D.; Fan, E.; Ferguson, N.D.; Brodie, D. Unproven and Expensive May Still Be Justifiable. Am. J. Respir. Crit. Care Med. 2018, 198, 140. [CrossRef]

27. Bein, T.; Weber-Carstens, S.; Goldmann, A.; Müller, T.; Staudinger, T.; Brederlau, J.; Muellenbach, R.; Dembinski, R.; Graf, B.M.; Wewalka, M.; et al. Lower tidal volume strategy $(\approx 3 \mathrm{~mL} / \mathrm{kg})$ combined with extracorporeal $\mathrm{CO}_{2}$ removal versus 'conventional' protective ventilation $(6 \mathrm{~mL} / \mathrm{kg})$ in severe ARDS: The prospective randomized Xtravent-study. Intensiv. Care Med. 2013, 39, 847-856. [CrossRef]

28. Rozencwajg, S.; Guihot, A.; Franchineau, G.; Lescroat, M.; Bréchot, N.; Hékimian, G.; Lebreton, G.; Autran, B.; Luyt, C.-E.; Combes, A.; et al. Ultra-Protective Ventilation Reduces Biotrauma in Patients on Venovenous Extracorporeal Membrane Oxygenation for Severe Acute Respiratory Distress Syndrome. Crit. Care Med. 2019, 47, 1505-1512. [CrossRef] [PubMed]

29. MacLaren, G.; Fisher, D.; Brodie, D. Preparing for the Most Critically Ill Patients with COVID-19: The Potential Role of Ex-tracorporeal Membrane Oxygenation. JAMA 2020, 323, 1245. [CrossRef] [PubMed]

30. Ramanathan, K.; Antognini, D.; Combes, A.; Paden, M.; Zakhary, B.; Ogino, M.; MacLaren, G.; Brodie, D.; Shekar, K. Planning and provision of ECMO services for severe ARDS during the COVID-19 pandemic and other outbreaks of emerging infectious diseases. Lancet Respir. Med. 2020, 8, 518-526. [CrossRef]

31. Loforte, A.; Di Mauro, M.; Pellegrini, C.; Monterosso, C.; Pelenghi, S.; Degani, A.; Rinaldi, M.; Stura, E.C.; Sales, G.; Montrucchio, G.; et al. Extracorporeal Membrane Oxygenation for COVID-19 Respiratory Distress Syndrome: An Italian Society for Cardiac Surgery Report. ASAIO J. 2021, 67, 385-391. [CrossRef]

32. Yang, X.; Hu, M.; Yu, Y.; Zhang, X.; Fang, M.; Lian, Y.; Peng, Y.; Wu, L.; Wu, Y.; Yi, J.; et al. Extracorporeal Membrane Oxygenation for SARS-CoV-2 Acute Respiratory Distress Syndrome: A Retrospective Study From Hubei, China. Front. Med. 2021, 7, 611460. [CrossRef]

33. Fang, J.; Li, R.; Chen, Y.; Qin, J.-J.; Hu, M.; Huang, C.-L.; Cheng, L.; He, Y.; Li, Y.; Zhou, Q.; et al. Extracorporeal Membrane Oxygenation Therapy for Critically Ill Coronavirus Disease 2019 Patients in Wuhan, China: A Retrospective Multicenter Cohort Study. Curr. Med. Sci. 2021, 41,1-13. [CrossRef]

34. Akhtar, W.; Olusanya, O.; Baladia, M.M.; Young, H.; Shah, S. SARS-CoV-2 and ECMO: Early results and experience. Indian J. Thorac. Cardiovasc. Surg. 2021, 37, 53-60. [CrossRef] [PubMed]

35. Dreier, E.; Malfertheiner, M.V.; Dienemann, T.; Fisser, C.; Foltan, M.; Geismann, F.; Graf, B.; Lunz, D.; Maier, L.S.; Müller, T.; et al. ECMO in COVID-19-Prolonged therapy needed? A retrospective analysis of outcome and prognostic factors. Perfusion 2021. [CrossRef]

36. Zayat, R.; Kalverkamp, S.; Grottke, O.; Durak, K.; Dreher, M.; Autschbach, R.; Marx, G.; Marx, N.; Spillner, J.; Kersten, A. Role of extracorporeal membrane oxygenation in critically Ill COVID-19 patients and predictors of mortality. Artif. Organs 2020. [CrossRef] 
37. Abrams, D.; Lorusso, R.; Vincent, J.-L.; Brodie, D. ECMO during the COVID-19 pandemic: When is it unjustified? Crit. Care 2020, 24, 1-3. [CrossRef] [PubMed]

38. Kowalewski, M.; Fina, D.; Słomka, A.; Raffa, G.M.; Martucci, G.; Coco, V.L.; De Piero, M.E.; Ranucci, M.; Suwalski, P.; Lorusso, R. COVID-19 and ECMO: The interplay between coagulation and inflammation-A narrative review. Crit. Care 2020, $24,205$. [CrossRef]

39. Tonna, J.E.; Abrams, D.; Brodie, D.; Greenwood, J.C.; Mateo-Sidron, J.A.R.; Usman, A.; Fan, E. Management of Adult Patients Supported with Venovenous Extracorporeal Membrane Oxygenation (VV ECMO): Guideline from the Extracorporeal Life Support Organization (ELSO). ASAIO J. 2021, 67, 601-610. [CrossRef]

40. Deana, C. The COVID-19 pandemic: Is our medicine still evidence-based? Ir. J. Med Sci. 2021, 190, 11-12. [CrossRef] 